\title{
Effect of salt and sugar osmotic stress on the viability and morphology of Saccharomyces boulardii
}

\author{
S.V. Ávila-Reyes ${ }^{1}$, B.H. Camacho-Díaz ${ }^{2}$, M.C. Acosta-García ${ }^{3}$, A.R. Jiménez-Aparicio ${ }^{2}$, H. \\ Hernández-Sánchez ${ }^{1 *}$
}

\begin{abstract}
${ }^{1}$ Departamento de Ingeniería Bioquímica, Escuela Nacional de Ciencias Biológicas, Instituto Politécnico Nacional, Unidad Profesional López Mateos, Av. Wilfrido Massieu esq. Cda. Manuel L. Stampa s/n, CP. 07738, Ciudad de Mexico, México. ${ }^{2}$ Laboratorio de Microscopía, CeProBi-IPN, Carr. Yautepec-Jojutla Km 6, Calle CeProBi No. 8, Col. San Isidro, Yautepec, CP. 62731 Mor., México.

${ }^{3}$ Laboratorio de Microscopía Electrónica, UAM-I, Av. San Rafael Atlixco No.186, Col. Vicentina, Delegación Iztapalapa, C.P. 09340, Ciudad de México, México.

*email: hhernan1955@yahoo.com
\end{abstract}

\begin{abstract}
Changes in the viability, composition and morphology of the probiotic yeast Saccharomyces boulardiiwerefollowed inhyperosmoticYPD broths withNaCland sucrosein concentration ranges from0.2 to 2M. Samples were observedbyscanning (SEM) and transmission (TEM) electron microscopy. SEM revealed changes inthe morphology (swelling) in the walls ofthe yeasts grown in high-osmolarity broths. TEM showed that, as a result of the high osmolarity, the cell wall was thickenedand vesicles were formed in the cytoplasm. The growth kinetics results indicated that $S$. boulardiicould be considered as anosmotolerantyeast, since it could still grow and reach concentrations of $3.4 \times 10^{5}$ and $3.6 \times 10^{7} \mathrm{CFU} / \mathrm{mL}$ at sucrose concentrations of $2.0 \mathrm{M}$ and 1.5Mrespectively. The results also suggested thatthis yeast could also be consideredhaloduric sincecell concentrationsof $3.9 \times 10^{6}$ and $3.4 \times 10^{5} \mathrm{CFU} / \mathrm{mLcould}$ be maintained in broths with 0.4 and $1.4 \mathrm{MNaCl}$ respectively. $S$. boulardii was still able to produce $0.5 \%$ ethanol in the $2.0 \mathrm{M}$ broth.
\end{abstract}

Keywords-osmotic stress, Saccharomyces boulardii, viability, trehalose, glycerol.

\section{INTRODUCTION}

Probiotics are defined by the FAO/ WHO (2002) as"those live microorganisms, which when administered in adequate amounts, confer a health benefit on the host". It has been reported that the numberof viable probiotics in a product at the time of consumption should be in the range of $1 \times 10^{7}-$ $1 \times 10^{9} \mathrm{CFU} / \mathrm{mL}$, but this depends on the species and strain.It is also required that the probiotic strain used be safe and of human origin (Makinen et. al., 2012).However, there are studies that show that there are probiotic strains of human intestinal and food origin, although it is not easy to maintain a permanent colonization of the intestinal tract by an exogenous strain (Gueimonde and Salminen, 2006). The most common probiotic microorganismsinclude strains of lactic acid bacteria, bifidobacteria and yeasts such as Saccharomyces boulardii, a non-pathogenic yeast, which is the only probiotic yeast approved by the FDA for human consumption (Zamith-Miranda et. al., 2016).

Today, there is more diversity in the food matrices that are intended to be used as vehicles for probiotic microorganisms, including formulations with high amounts of ionic (mainly $\mathrm{Na}$ salts) and nonionics (mainly sucrose and polyols)solutes. These compounds have been used for centuries to provide taste and as food preservatives (SunnyRoberts and Knorr, 2008), since these solutes are able to reduce thewater activity $\left(\mathrm{a}_{\mathrm{w}}\right)$ of foods and are the major abiotic stressors that reduce the growth of yeasts in foodsby maintaining a high osmolarity in the medium(Dakal et. al., 2014). Nevertheless, the growth and survival in each environmental niche, depend on the ability of each genus and strain of yeast to detect and respond to osmotic stress conditions, as this causes water to be expelled from the cell and result in an increase in the concentration of ions and metabolites and decreased cellular activity. Francois (2016)has described the way in which yeast cells reorganize the integrity and fluidity of their plasma membrane to produce changes in the cell wall nanomechanical properties.It is assessed that about 200 genes are involved in encoding enzymes involved in the biogenesis and 
remodelling of the cell wall in yeasts. These changes are aimed at establishinga balance by which the force pushing water across the osmotic gradient into the yeast cell is neutralized by turgor pressure against the plasma membrane and cell wall (Levin, 2011). Specific differences of each yeast strain, also have been described at the level of the inner layer of the B-D-glucans and mannans of the cell wall. However, further research is still required to identify the factors affecting the resistance mechanisms and kinetic changes in the growth ofmicroorganisms(Jordan et. al., 2008).Exposure of yeast cells to conditions of high concentrations of ionic and nonionic solutes during fermentation, involves several metabolic activities whichinduce specific cellular adaptation capacities to the sudden and severe fluctuations in water availability to restore or maintain normal biochemical and physiological functions(Guerzoni et al., 2007; Dakalet al.,2014).

In this study, morphological changes and survival of the probiotic yeast Saccharomyces boulardii under conditions of osmotic stress with sodium chloride and sucrose were evaluated. The results of their adaptation to this type of stress can be used to determine more accurately their technological use in the food industry.

\section{MATERIALS AND METHODS}

\section{Yeast strain and growth conditions}

The strain of probiotic yeast Saccharomyces boulardii (Hansen CBS 5926) used was isolated from Floratil@(Merk, S.A. de C.V., México). The freeze-dried content of a capsule was emptied into $100 \mathrm{ml}$ of YPD broth $(0.05 \% \mathrm{NaCl}, 1 \%$ glucose, $0.5 \%$ peptone, and $0.5 \%$ yeast extract) and incubated over-night at $37^{\circ} \mathrm{C}$. The yeast wasthen grown in YPD agar slants and kept refrigerated and the procedure repeatedapproximately every two months to keep them in a viable state (active). Cells were grownroutinely in $250 \mathrm{~mL}$ flasks to $37^{\circ} \mathrm{C}$ over a period of $16 \mathrm{~h}$. Cells were kept frozen at $-20^{\circ} \mathrm{C}$ in YPDbroth supplemented with $50 \%$ glycerol (v/v).

\section{High osmolarity culture preparation}

The high osmolarity medium was prepared by adding the necessary amount of $\mathrm{NaCl}$ or sucrose in a $100 \mathrm{~mL}$ volumetric flask to reach concentrations for 0.2 to $2 \mathrm{M}$. YPD broth was used to dissolve the solute. The modified medium was sterilized in Erlenmeyer flasks and inoculatedwith $5 \%$ of a suspension of $S$. boulardii, previously activated and adjusted to an OD of 1 at $640 \mathrm{~nm}$. Subsequently, the medium was incubated at $37^{\circ} \mathrm{C}$ for $24 \mathrm{~h}$ andthe growth (measured as absorbance) was monitored spectrophotometrically at $640 \mathrm{~nm}$ (Spectrophotometer6405 UV/Vis, JENWAY)and the $\mathrm{pH}$ measured.

\section{Determination of alcohol content}

The distillation method described in the Mexican Standard NMX-V-043-1972 was followed. A sediment free sample $(60 \mathrm{~mL})$ of fermented medium was taken and its temperatureadjusted to $20{ }^{\circ} \mathrm{C}$. It was quantitatively transferred to a distillation flask with $60 \mathrm{~mL}$ of water, which was connected to a refrigerant and to a condensation flask. Boiling was suspended when a condensate volume of approximately $70 \mathrm{~mL}$ was reached. The flask content was emptied into a graduated measuring cylinder and the reading taken with a Gay Lussac densimeter at a temperature of $15^{\circ} \mathrm{C}$.

Acetic acid determination by HPLC

The fermentedsugar osmotic stress broths were analyzed for acetic acid, following the method of Zheng et al. (2008). Chromatographic separation was performed on a Varian 920 LC HPLC system (Varian Inc., Palo Alto, California, USA) provided with a diode array detector (PDA) and quaternary pump. The column used a support containing C18 $5 \mu \mathrm{M}$, 4.6 x $250 \mathrm{~mm}$ (XSelect ${ }^{\circ}$ HSS T3, Waters, Milford, MA, USA) and placed in an oven at a temperature of $30{ }^{\circ} \mathrm{C}$. The injection volume was $20 \mu \mathrm{L}$ for all samples and the time of each run of $18 \mathrm{~min}$, by passing the solvent (mobile phase) at a rate of isocratic flow of $0.8 \mathrm{~mL} \mathrm{~min}^{-1}$, consisting of $5 \%$ acetonitrile and $95 \% 0.01 \mathrm{M} \mathrm{KH}_{2} \mathrm{PO}_{4}$ in water ( $\mathrm{pH}$ 2.7). The samples were centrifuged at $12,000 \mathrm{x} \mathrm{g}$ for $15 \mathrm{~min}$ at $4{ }^{\circ} \mathrm{C}$, of the supernatant was taken an aliquoted and diluted in a 1: 5 with mobile phase solution. Prior to injection, $20 \mu \mathrm{L}$ was filtered through a $0.22 \mu \mathrm{m}$ membrane for aqueous solvents (tetrafluoroethylene filter, Gelman/ Pall Life Sciences, Michigan, USA).

Biomass and intracellularglycerol and trehalose content. $S$. boulardiicells cultured under osmotic stress were harvested via centrifugation at $10,000 \mathrm{x} \mathrm{g}$ for $5 \mathrm{~min}$. For determination of intracellular glycerol, cell pellets were washed twice with $2 \mathrm{~mL}$ distilled water and resuspended inPBSto a final volume of $2 \mathrm{ml}$ (Kobayashi et. al., 2013). For dry cell weight determination, $1 \mathrm{~mL}$ of the cell suspension was kept at $80^{\circ} \mathrm{C}$ for $12 \mathrm{~h}$. The other $\mathrm{ml}$ of suspension was transferred into a new tube,centrifuged and the pellet resuspended in $1 \mathrm{~mL}$ boiling $0.5 \mathrm{M}$ Tris/ $\mathrm{HCl}$ buffer ( $\mathrm{pH}$ 7.0) for $20 \mathrm{~min}$. The cells debris were removed by centrifugation and the glycerol concentration was determined enzymatically in the supernatant (Cayman Chemical, Kit No. 10010755). For determination of the intracellular trehalose,the cells pellet was resuspended in 1 $\mathrm{mL}$ of $0.25 \mathrm{M} \mathrm{NaCO}_{3}$, the suspension was incubated at 100 ${ }^{\circ} \mathrm{C}$ for $20 \mathrm{~min}$, then cooled and centrifuged for 10 minutes at 15,000xg (Housa et. al., 1998). An aliquot of $200 \mu \mathrm{L}$ of the supernatant was taken and neutralized by addition of 
$100 \mu \mathrm{L}$ of $1 \mathrm{M}$ acetic acid and $100 \mu \mathrm{L}$ of Buffer T (300 mM sodium acetate and $30 \mathrm{mM}$ calcium chloride, $\mathrm{pH}$ 5.5). An aliquot of $100 \mu \mathrm{L}$ of this mixture was incubated in the presence of $50 \mu \mathrm{L}$ of trehalase (Sigma T-8778 No., diluted 1:3) for 6 hours at $37^{\circ} \mathrm{C}$. The reaction was stopped by incubation of the sample at $100{ }^{\circ} \mathrm{C}$ for $10 \mathrm{~min}$. The glucose released from the trehalose was estimated by the glucose oxidase and peroxidase method (Glucose PAP SL, GPSL0507, ELI Tech, SEES-France) following the manufacturer's instructions.

\section{TEM and SEM observations}

The steps in preparing of $S$. boulardii cellsin TEM and SEM analyses, were: One milliliter of the cells pellet was washed twice with $0.1 \mathrm{M}$ phosphate buffer $\mathrm{pH} 7.3-7.4$ (Sorenson solution) to remove traces of the culture medium, centrifuged each time at 5040xg to remove the supernatant and subsequently fixed in $3 \%$ glutaraldehyde solution in $0.1 \mathrm{M}$ phosphate buffer for 12 hours. After this time, the cells were washed with $0.1 \mathrm{M}$ phosphate buffer $\mathrm{pH} 7.2$ to remove glutaraldehyde and centrifuged at $5000 \mathrm{rpm}$ for 5 minutes. In each wash the cells were allowed to stand for 30 minutes. They were contrasted with osmium tetroxide and subsequently dehydratedwith ethyl alcohol at different concentrations $(20,30,40,50,70,80$ and 100\%). In the case of TEM analyses, after the ethanol treatments, two washes with ACN 100\% were performed before making their inclusion in resin-acetonitrile (1: 1) for $48 \mathrm{~h}$ in a desiccator and then only with resin, left to stand for $48 \mathrm{~h}$ in the oven at $60^{\circ} \mathrm{C}$. Ultrathin sections, were contrasted with uranylacetate for further observation in TEM. In the case of SEM analyses, ethanol was removed from the cells with the aid of a critical point dryer, and then the dry sample was placed on a copper and carbon tape covered with gold before observation under a JEOL JSM-7800F SEM. (Vazquez-Nin and Echeverria, 2000).

\section{RESULT AND DISCUSSION}

\section{Yeast cell viability under osmotic stress}

Survival to osmotic stress of $S$. boulardii in YPD broth, modifiedto reach concentrations ranging from 0.2 to $1.4 \mathrm{M}$ $\mathrm{NaCl}$,was evaluated (Fig. 1a). In the $0.2 \mathrm{M}$ broth, the logarithmic phase started after 4 hours of fermentation and lasted around $8 \mathrm{~h}$, reaching a population of $7.08 \mathrm{log}$ $\mathrm{CFU} / \mathrm{mL}$, while in the condition of $0.4 \mathrm{M}$ the population reached $6.59 \log \mathrm{CFU} / \mathrm{mL}$ after 24 hours of fermentation. $\mathrm{NaCl}$, in the concentration range of $0.6 \mathrm{M}$ to $1.4 \mathrm{M}$, showed a zymostatic effect towards $S$. boulardiisince the yeast had greater difficulty to withstand and adapt to the osmotic stress generated by ionic solutes. $S$. boulardii, then, could be considered as ahaloduric yeast, that is, a microorganism that can survive in high salt concentrations but cannot grow. Most bacteria and fungi use the strategy of compatible solutes buildup for keeping their intracellular concentrations of $\mathrm{Na}^{+}$underneath toxic levels. It has been reported that the salt-sensitive yeastSaccharomyces cerevisiae almost exclusively uses glycerol as the compatible solute (GundeCimerman et al., 2009). At $34^{\circ} \mathrm{C}$, concentrations of $1.5 \mathrm{M}$ or higher of $\mathrm{NaCl}$ inhibited the growth of $S$. cerevisiae (Almagro et al., 2000), showing a similar behavior to $S$. boulardii in this study. Papouskova and Sychrova (2007) showed that the co-action of osmotic and high temperature stresses actually results in growth improvement in Debaryomyces hansenii so the influence of combined stress situations must be studied also.

In the case of sucrose, the stress evaluation was performed at a concentration range of 0.2 to $2.0 \mathrm{M}$ (Figure 1b).A similar trend was observed at concentrations of 0.2 to $0.6 \mathrm{M}$ (7-20\% sucrose) with respect to the control, with longerlag and $\log$ phases.Populations of $7.45 \mathrm{log} \mathrm{CFU} / \mathrm{mL}$ and $7.3 \mathrm{log}$ $\mathrm{CFU} / \mathrm{mL}$ after 10 and $20 \mathrm{~h}$ of fermentation were reached in the control and in the $0.6 \mathrm{M}$ concentration respectively. When the sucrose concentration was increased to $0.9 \mathrm{M}$ and $1.5 \mathrm{M}$ (30 and 50\% sucrose)similar populations could only be reached after 24 and $30 \mathrm{~h}$ respectively. $S$. boulardii had a high tolerance to sugar osmotic stress and could be considered as an osmoduric yeast since it presented viability and a feeble growth even at concentrations of 1.8 and $2.0 \mathrm{M}$ (> 60\%), indicating that none of the concentrations evaluated in this assay managed to have a complete inhibitory effect. In general, increasing the concentration of the osmolyte resulted in an increase in the duration of the lag and log phases. The ethanol concentration (Table 1) was also measured and the highest concentrations were obtained in the 0.4 and $0.6 \mathrm{M}$ sucrose broths ( $8 \%$ alcohol) after $24 \mathrm{~h}$ of fermentation.The presence of a large amount of $\mathrm{CO}_{2}$ could also be observed.Ethanol $(0.5 \%)$ could still be produced even at concentrations of $1.8 \mathrm{M}$ and $2.0 \mathrm{M}$ after $36 \mathrm{~h}$ of fermentation. This behavior reflects thefact that the cells still retain their fermentation capacity even at the low concentration of $5.4 \log \mathrm{CFU} / \mathrm{mL}$. Hernandez-Lopez et al. (2003) found that, in the case ofTorulaspora delbrueckii and $S$. cerevisiae, the exposure tothe hyperosmotic stress of bread dough containing $20 \%(0.62 \mathrm{M})$ sucrose resulted in a dramatic drop of the fermentative capacity. This confirms the higher osmotolerance of the $S$. boulardii strain of this study.

\section{Trehalose and glycerol accumulation in yeast cells}

Acetate was measured in the YPD broths after $24 \mathrm{~h}$ of fermentation only as an indication that it was being 
produced and that the yeast cells could also be accumulating it intracellularly. The acetate concentrations were 1.16, 2.85 , and $2.22 \mathrm{mg} / \mathrm{mL}$ in the broths with $0,0.9$, and $1.8 \mathrm{M}$ sucrose concentrations respectively, indicating that the high sugar stress increases the synthesis of acetate for a possible use as an osmotic protectant. Trehalose and glycerol function as potential stress protectants by preserving the integrity of the plasma membrane and stabilizing the proteins (Wang et al., 2014). Under stress-free conditions, trehalose starts accumulatingwhen cells enter the stationary phase and contributes to survival in the stressful conditions of this growth phase.Recently, it has been shown that, in the case of $S$. cerevisiaeunder saline stress conditions, there is anincreased expression of the genes encoding the enzymes involved in trehalose, glycerol and acetate syntheses (Mahmud et al., 2009). These facts support the idea that these compounds play important roles in osmotic tolerance. The presence of acetate as a stress protectant is important since organic acids produced during fermentation (lactic, acetic, and succinic acids) by yeasts account for a significant fraction of the metabolic products (Zheng et al., 2009).

The intracellular trehalose and glycerol contents were determined after the cultures entered the stationary phase (see Table 2).The increased levels of trehalose detected in the case of the $\mathrm{NaCl}$ osmotic stress, indicates that $S$. boulardii behaves in a similar way as $S$. cerevisiae (Mahmud et al., 2009) when exposed to saline stress and synthesize trehalose to be used as a protectant. On the other hand, the trehalose levels obtained in the culture media with sucrose were similar to those of the control indicating that, unlike $S$. cerevisiae (Wang et al., 2014), S. boulardii does not use the production of trehalose as a strategy to tolerate osmotic stress. Yoshiyama et al. (2015) related the amount of accumulated intracellular trehalose $(0.6 \mathrm{mg} / \mathrm{g})$ in $S$. cerevisiae with an enhanced tolerance to acetic acid. Hounsa et al. (1998) found, also in S. cerevisiae under osmotic stress with $\mathrm{NaCl}$ and sorbitol, values of trehalose of 2.52 and $2.56 \mathrm{mg} / \mathrm{g}$ biomass respectively in the stationary phase. Several authors (Yoshiyama et al, 2015; Malgorzata et al, 2015; Hounsa et al, 1998) have indicated that the concentration of intracellular trehalose is directly related to cell survival, however, this is not universal as in the case of $S$. boulardii under osmotic stress.

Glycerol, the main compatible solute in $S$. cerevisiae, is accumulated intracellularly when the yeast is exposed to osmotic stress (Nevoigt and Stahl, 1997). In this study (Table 2), the glycerol intracellular levels increased with the severity of the saline or osmotic stress.Similar results were reported by Pigeau and Inglis, (2007) where higher levels of glycerol were detected in yeast fermentations with high sugar content $(1.2 \mathrm{M})$ compared to fermentations witha lower sugar content $(0.6 \mathrm{M})$.An increase in glycerol intracellular concentration was also reported in the case of the yeast Saccharomycopsis fibuligera when subjected, as in this study, to high salt concentrations $(0.5$ and $1 \mathrm{M})$ in YPD media (Yan et al., 2008).

\section{Effect of osmotic stress on the cell morphology of $S$. boulardii}

In the SEM micrographs, the cells subjected to osmotic stress (Fig.2c-f) show no apparent change in size with respect to thestress-free cells (Fig. 2a-b). In the yeasts with salt stress treatment, cells with wrinkles and with diverse degrees of plasmolysis can be observed (Fig. 2c-d). In the cells subjected to osmotic stress with sucrose, no differences can be observed with respect to the control with the exception of a slightly rougher surface.Similar results were observed by Dakal et al. (2014) with the yeastZygosaccharomyces rouxii. Figures3a-b show TEM micrographs of cells of $S$. boulardii untreated, where a typical structure and a regularly stained cytoplasm with a high electron density and a well-defined ultrastructure can be observed. With the increase insalt or sucrose concentration, cells have a tendency to retain nutrients in order to keep the intracellular homeostasis; this process results in the generation of reserve vesicles as shown in Figures $3 \mathrm{c}$ and $3 \mathrm{e}$. In the case of Figure $3 \mathrm{c}(1.4 \mathrm{M} \mathrm{NaCl})$, a greater damage is observed with the presence of membranous bodies and structural disorder in the cytoplasm and a cell generally less electrodense. Figure $3 \mathrm{~d}$ shows a more elongated cell but not too different from the control. Figure $3 \mathrm{e}$ (1.8M sucrose) shows the cell wall surrounded by an outer and an inner dark thick coat not observed in the other cases. This extra double barrier could help the cell to avoid the plasmolysis phenomenon observed in hypertonic media. In all stress conditions a thickened and electrondense cell wall was observed.Yeast cell walls have an inner matrix of interlinked $\beta$-glucan and chitin to offer rigidity and tensile strength. Yeast cells are known to be able to remodel their cell walls with time in response to osmotic and other environmental stresses (Ene et al., 2015). AguilarUscangaet al. (2005) observed that the variation in composition of the polysaccharides of the cell wall in $S$. cerevisiae plays an important role during cell formation.Dakal et al. (2014) determined that in the presence of high concentrations of extracellular solutes, cells undergo important physiological variationssuch as changes in the chemical and physical structure of the plasma membrane and cell wall and alteration in theosmotic pressure and volume of the cell wall. The first studies 
inZygosaccharomyces rouxii suggested that,in the presence of salt, the concentration of mannans of the cell wall decreased (Hosono, 1992).In the case ofSaccharomyces pombe and Saccharomyces cerevisiae, signaling pathways known as cell wall integrity pathways have been localized for the regulation of changes in the cell wall (CWI) (Klis et al., 2006; Madrid et al., 2006; Levin, 2011).

\section{CONCLUSIONS}

The above results showed that the accumulation of osmotically compatible metabolites such as trehalose and glycerol is very important for the survival of cells and for maintaining the stability and functionality of the cell wall and plasma membrane. An increased intracellular glycerol content was consistent with the presence of high concentrations of salt or sugar in the environment whereas trehalose was produced in a larger amount only in salt stress conditions. High sugar stress increased the synthesis of acetate for a possible use as an osmotic protectant. Changes at the ultrastructural level in $S$. boulardii cells were more evident in the case of $\mathrm{NaCl}$, where plasmolysis could be observed, than in sucrose osmotic stress.

\section{ACKNOWLEDGEMENTS}

Theauthorsacknowledge the support provided by a research grant from SIP-IPN and by scholarships from CONACYT and BEIFI-IPN for author Ávila-Reyes.The help of the TEM Unit of Centro de Nanociencias y Micro y Nanotecnología-IPN and Central of Microscopy of ENCBIPN is sincerely appreciated.

\section{REFERENCES}

[1] Aguilar- Uscanga, B.; Solis-Pacheco, J.; Francois, J. 2005. Estudio de la variación de la composición de los polisacáridos contenidos en la pared celular de la levadura Saccharomyces cerevisie. E-Gnosis. 3 (12)

[2] Almagro, A., Prista, C., Castro, S., Quintas, C., Madeira-Lopes, A., Ramos, J., Loureiro-Dias, M.C. 2000. Effects of salts on Debaryomyces hansenii and Saccharomyces cerevisiae under stress conditions. International Journal of Food Microbiology. 56: 191197.

[3] Dakal, T.C., Solieri, L. Giudici, P. 2014. Adaptive response and tolerance to sugar and salt stress in the food yeast Zygosaccharomyces rouxii. International Journal of Food Microbiology. 185: 140 - 157.

[4] Ene, L.V., Walker, L.A., Schiavone, M., Lee,,K.K., Martin-Yken, H., Dague, E., Gow, N.A.R., Munro, C.A., Brown, A.J.P. 2015. Cell wall remodeling enzymes modulate fungal cell wall elasticity and osmotic stress resistance. mBio 6(4): e00986-15

[5] FAO/WHO. 2002. Guidelines for the Evaluation of Probiotics in Food. (http://www.who.int/foodsafety/fs_management/en/pr obiotic guidelines.pdf)

[6] Francois, J.M. 2016. Cell surface interference with plasma membrane and transport processes in yeasts. In Yeast Membrane Transport. Eds. José Ramos, Hana Sychrová, Maik Kschischo. Volume 892 of the series Advances in Experimental Medicine and Biology, pp 11-31.

[7] Gueimonde, M., Salminen, S. 2006. New methods for selecting and evaluating probiotics. Digestive and liver disease: official journal of the Italian society of gastroenterology and the Italian Association for the study of the liver. 2: S242-S247.

[8] Guerzoni, M.E., Vernocchi, P., Ndagijimana, M., Gianotti, A., Lanciotti, R., 2007. Generation of aroma compounds in sourdough: effects of stress exposure and lactobacilli-yeasts interactions. Food Microbiology. 24: 139-148.

[9] Gunde-Cimerman, N., Ramos, J., Plemenitas, A. 2009. Halotolerant and halophilic fungi. Mycological Research. 113: 1231-1241.

[10] Hernández-López, M.J., Prieto, J.A., Randez, F. 2003. Osmotolerance and leavening ability in sweet and frozen sweet dough. Comparative analysis between Torulaspora delbrueckii and Saccharomyces cerevisiae baker's yeast strains. Antonie van Leeuwennhoek. 84: 125-134.

[11] Hosono, K. 1992. Effect of salt stress on lipid composition and membrane fluidity of the salt-tolerant yeast Zygosaccharomyces rouxii. Journal of General Microbiology. 138: 91 - 96.

[12] Hounsa. C.G.; Brandt, E.V.; Thevelen, J.; Hohmann, S.; Prior, B.A. 1998. Role of trehalose in survival of Saccharomyces cerevisiae under osmotic stress. Microbiology. 144: 671 - 680.

[13] Jordan, S., Hutchings, M.I., Mascher, T., 2008. Cell envelope stress response in Gram-positive bacteria. FEMS Microbiology Reviews. 32: 107-146.

[14] Klis, F.M., Boorsma, A., De Groot, P.W. 2006. Cell wall construction in Saccharomyces cerevisiae. Yeast. 23: $185-202$.

[15] Kobayashi, Y., Yoshida, J., Iwata, H., Koyama, Y., Kato, J., Ogihara, J., Kasumi, T. 2013. Gene expression and function involved in polyol biosynthesis of Trichosporonoides megachiliensis 
under hyper-osmotic stress. Journal of Bioscience and Bioengineering. 115: $645-650$.

[16] Levin, D.E., 2011. Regulation of cell wall biogenesis in Saccharomyces cerevisiae: the cell wall integrity signaling pathway. Genetics 189: 1145-1175.

[17] Madrid, M., Soto, T., Khong, H.K., Franco, A., Vicente, J., Pérez, P., Gacto, M., Cansado, J., 2006. Stress-induced response, localization, and regulation of the Pmk1 cell integrity pathway in Schizosaccharomyces pombe. Journal of Biological Chemistry 281: 2033-2043.

[18] Mahmud, S.A., Nagahisa, K., Hirasawa, T., Yoshikawa, K., Ashitani, K., Shimizu, H. 2009. Effect of trehalose accumulation on response to saline stress in Saccharomyces cerevisiae. Yeast 26: 17-30.

[19] Makinen, K., Berger, B., Bel-Rhlid, R., Ananta, E. 2012. Science and technology for the mastership of probiotic applications in food products. Journal of Biotechnology. 162: 356 - 365 .

[20] Malgorzata, K.L.; Gorka, A.; Gonchar, M. 2015. Simple assay of trehalose in industrial yeast. Food Chemistry. 158: 335 - 339.

[21] Nevoigt, E., Stahl, U. 1997. Osmoregulation and glycerol metabolism in the yeast Saccharomyces cerevisiae. FEMS Microbiology Reviews 21: 231-241.

[22] Papouskova, K., Sychrova, H. 2007. The co-action of osmotic and high temperature stresses results in a growth improvement of Debaryomyces hansenii cells. International Journal of Food Microbiology. 118: 1 7.

[23] Pigeau, G.M., Inglis, D.L. 2007. Response of wine yeast (Saccharomyces cerevisiae) aldehyde dehydrogenases to acetaldehyde stress during Icewine fermentation. Journal of Applied Microbiology. 103: 1576 - 1586.

[24] Sunny-Roberts, E.O. and Knorr, D. 2008. Evaluation of the response of Lactobacillus rhamnosus VTT E-
97800 to sucrose-induced osmotic stress. Food Microbiology. 25: 183-189.

[25] Vázquez-Nin, G., Echeverría, O. 2000. Introducción a la microscopía electrónica aplicada a las ciencias biológicas. Fondo de la Cultura Económica. Universidad Nacional Autónoma de México, Facultad de Ciencias, Ciudad Universitaria, México, D.F. Pág. 54-55.

[26] Wang, P.M., Zheng, D.Q., Chi, X.Q., Li, O., Qian, C.D., Liu, T.Z., Zhang, X.Y., Du, F.G., Sun, P.Y., Qu, A.M., Wu, X.C. 2014. Relationship of trehalose accumulation with ethanol fermentation in industrial Saccharomyces cerevisiae yeast strains. Bioresource Technology. 152: $371-376$.

[27] Yan, H., Jia, L.H., Lin, Y.P., Jiang, N. 2008. Glycerol accumulation in the dimorphic yeast Saccharomycopsis fibuligera: cloning of two glycerol 3-phosphate dehydrogenase genes, one of which is markedly induced by osmotic stress. Yeast 25: 609621.

[28] Yoshiyama, Y.; Tanaka, K.; Yoshyama, K.; Hibi, M.; Ogawa, J.; Shima, J. 2015. Trehalose accumulation enhances tolerance of Saccharomyces cerevisiae to acetic acid. Journal of Bioscience and Bioengineering. 2: $172-175$.

[29] Zamith, D., Palma, M.L., Matos, G.S., Schiebel, J.G., Maya, C.M., Aronovich, M., Bozza, P.T., Bozza, F.A., Nimrichter, L., Montero, M., Marques, E.T., Martins, F.S., Douradinha, B. 2016. Lipid droplet levels vary heterogeneously in response to simulated gastrointestinal stresses in different probiotic Saccharomyces cerevisiae strains. Journal of Functional Foods. 21: 193 - 200.

[30] Zheng, Y. J., Duan, Y. T., Zhang, Y. F., Pan, Q. H., Li, J. M., Huang, W. D. 2009. Determination of organic acids in red wine and must on only one RPLC-column directly after sample dilution and filtration. Chromatographia. 69: 1391-1395. 

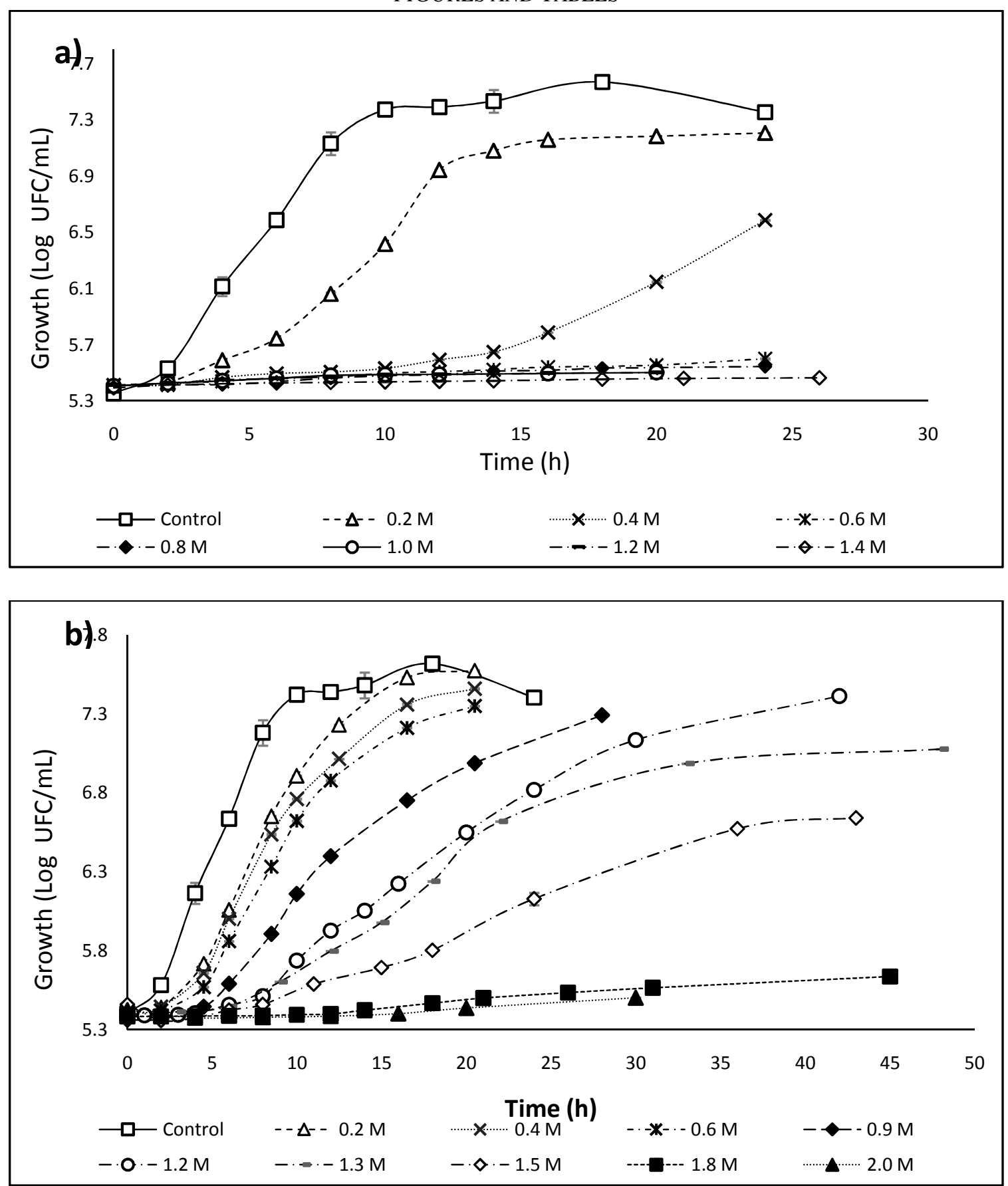

Fig. 1:Saccharomyces boulardiisurvival under different conditions of osmotic stress: a) NaCl and b) Sucrose. 

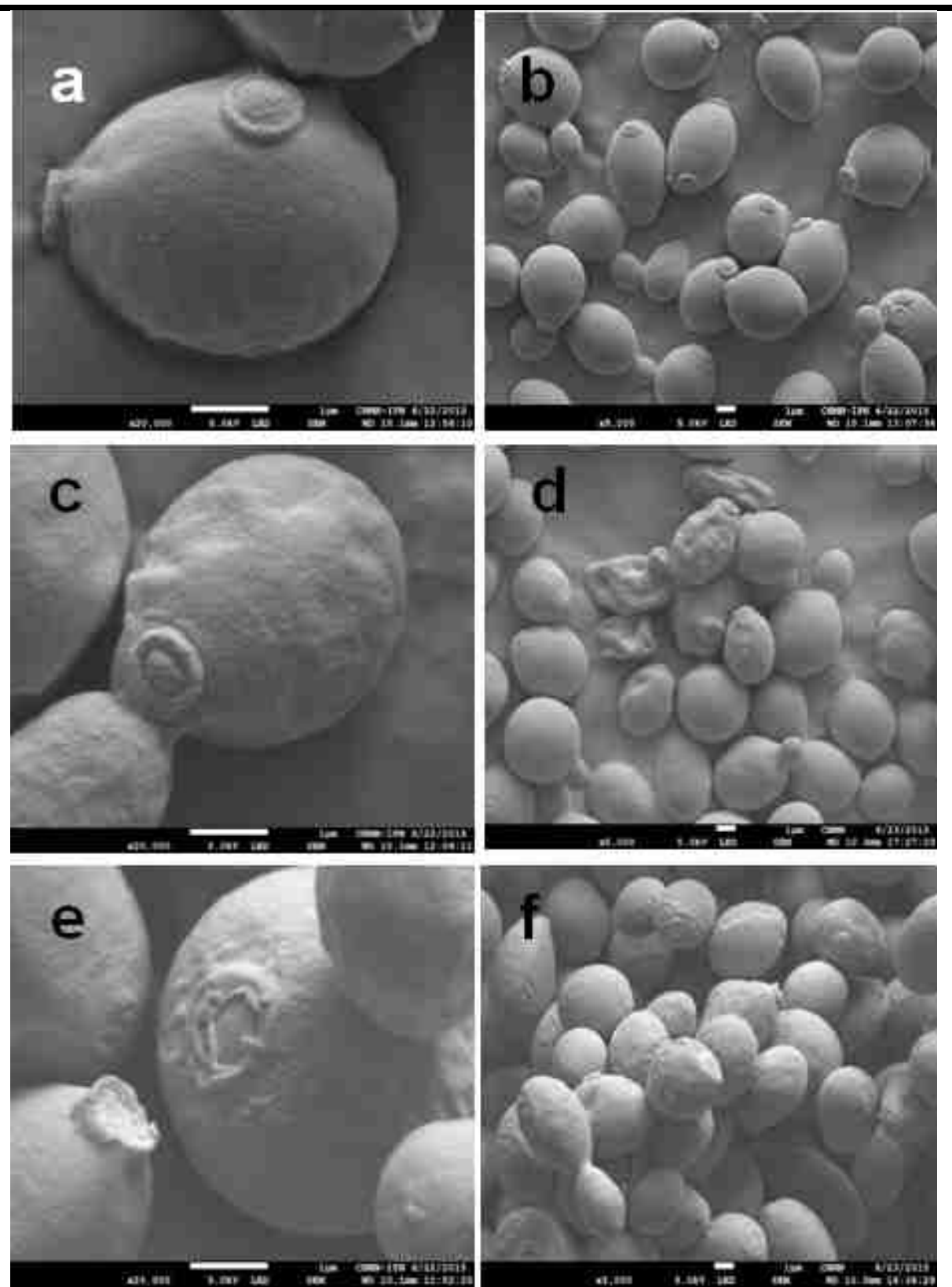

Fig.2: Scanning electron micrograph of S. boulardii, a) and b) control cells, c) and d) grown in $1.4 \mathrm{M} \mathrm{NaCl} \mathrm{YPD} \mathrm{broth} \mathrm{e)} \mathrm{and} \mathrm{f)}$ grown in1.8 M sucrose YPD broth. Magnification is 20000x, white bar indicates $1 \mu \mathrm{m}$. 

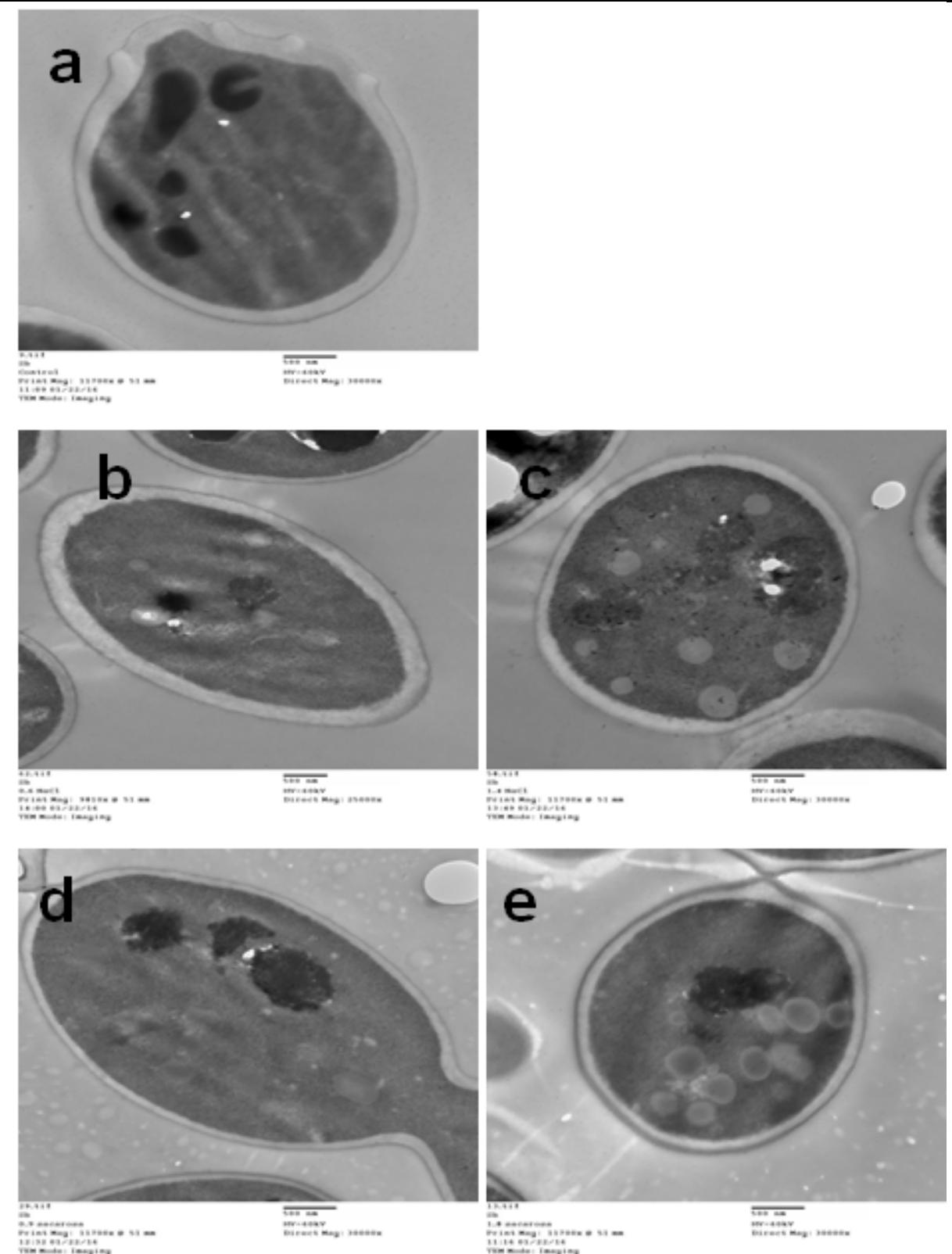

Fig.3: Transmission electron micrograph of $\mathrm{S}$. boulardii a) control, b) grown in $0.6 \mathrm{M} \mathrm{NaCl} \mathrm{YPD} \mathrm{broth} \mathrm{(c)} \mathrm{grown} \mathrm{in} 1.4 \mathrm{M} \mathrm{NaCl}$ YPD broth (d) grown in $0.9 \mathrm{M}$ sucrose YPD broth and (e) grown in1.8 M sucrose YPD broth. Magnification is 60,000x, black bar is $500 \mu \mathrm{m}$.

Table.1: Alcohol content in fermented YPD broth at different sucrose concentrations

\begin{tabular}{ccc}
\hline Sucrose concentration & $\begin{array}{c}\text { Alcohol } \\
(\mathrm{mg} / \mathrm{mL})\end{array}$ & $\begin{array}{c}\text { Alcohol } \\
(\% \mathrm{v} / \mathrm{v})\end{array}$ \\
\hline $0.2 \mathrm{M}$ & 39.5 & 5 \\
$0.4 \mathrm{M}$ & 63.1 & 8 \\
$0.6 \mathrm{M}$ & 63.1 & 8 \\
$0.9 \mathrm{M}$ & 59.2 & 7.5 \\
$1.2 \mathrm{M}$ & 39.5 & 5
\end{tabular}




\begin{tabular}{lcc}
$1.3 \mathrm{M}$ & 35.5 & 4.5 \\
$1.5 \mathrm{M}$ & 35.5 & 4.5 \\
$1.8 \mathrm{M}$ & 11.8 & 1.5 \\
$2.0 \mathrm{M}$ & 3.9 & 0.5 \\
\hline
\end{tabular}

Table.2: Mean intracellular trehalose and glycerol content in S. boulardii at different concentrations of NaCl and sucrose in YPD medium at the stationary phase

\begin{tabular}{ccc}
\hline Treatment & $\begin{array}{c}\text { Trehalose content } \\
(\mathrm{mg} / \mathrm{g} \text { dry weight })\end{array}$ & $\begin{array}{c}\text { Glycerol content } \\
(\mathrm{mg} / \mathrm{g} \text { dry weight })\end{array}$ \\
\hline Control & $0.25 \pm 0.007$ & $12.35 \pm 0.685$ \\
$\mathrm{NaCl} \mathrm{0.6} \mathrm{M}$ & $0.58 \pm 0.009$ & $192.34 \pm 2.102$ \\
$\mathrm{NaCl} \mathrm{1.4} \mathrm{M}$ & $1.16 \pm 0.007$ & $872.15 \pm 2.809$ \\
Sucrose 0.9 M & $0.23 \pm 0.002$ & $206.87 \pm 4.314$ \\
Sucrose 1.8 M & $0.32 \pm 0.013$ & $791.64 \pm 2.506$ \\
\hline
\end{tabular}

\footnotetext{
* Values are mean $\pm \mathrm{SD}, \mathrm{n}=2$
} 